Article

\title{
Electrochemical Detection of Chloride Ions by Copper (II) Complex with Mixed Ligand of Oxindole Derivative and Dithiocarbamates Moiety
}

\author{
M. Nazim ${ }^{1,+}$, Abdullah ${ }^{1,+}$, Sadia Ameen ${ }^{2, *}$, M. Shaheer Akhtar ${ }^{3}$ and Hyung-Shik Shin ${ }^{1, *(1)}$ \\ 1 Energy Materials \& Surface Science Laboratory, Solar Energy Research Center, School of Chemical \\ Engineering, Chonbuk National University, Jeonju 54896, Korea; nazim@jbnu.ac.kr (M.N.); \\ abdullahazmi@jbnu.ac.kr (A.) \\ 2 Advanced Materials and Devices Laboratory, Jeongeup Industry-Academic Cooperation Support Centre, \\ Jeongeup Campus, Chonbuk National University, Jeongeup 56212, Korea \\ 3 New \& Renewable Energy Material Development Center (NewREC), Chonbuk National University, \\ Jeonbuk 56332, Korea; shaheerakhtar@jbnu.ac.kr \\ * Correspondence: sadiaameen@jbnu.ac.kr (S.A.); hsshin@jbnu.ac.kr (H.-S.S.) \\ + Authors are equally contributed in this work.
}

Received: 16 January 2019; Accepted: 22 March 2019; Published: 31 March 2019

\begin{abstract}
The present work describes the synthesis of a new copper (II) complex with bidentate ligands based on oxindole (indolin-2-one) derivatives, namely: $1 H, 1^{\prime} H, 1^{\prime \prime} H-\left[2,3^{\prime}: 2^{\prime}, 3^{\prime \prime}\right.$ terbenzo[b]pyrrol]-2" $\left.2^{\prime \prime} 3^{\prime \prime} H\right)$-one (L1) and [sodium diethyldithiocarbamate (DTC)] (L2) as a second bidentate ligand. The ligand L1 was prepared by the cyclization reaction of oxindole (2-indolone) with phosphorus oxychloride. A mixed-ligand was synthesized using L1 and L2 ligands with copper $\left(\mathrm{Cu}\right.$ (II)) via a simple reflux process. The synthesized mixed $\mathrm{Cu}$ (II) complex $\left[\mathrm{C}_{53} \mathrm{H}_{44} \mathrm{CuN}_{7} \mathrm{O}_{4} \mathrm{~S}_{2}\right.$ and $\left.\left[\mathrm{Cu}(\mathrm{L} 1)_{2}(\mathrm{~L} 2)\right] 2 \mathrm{H}_{2} \mathrm{O}\right]$ exhibited superior solubility in organic solvents like dichloromethane, chloroform, ethanol, methanol, DMF and DMSO. The optical characterizations revealed that the synthesized $\mathrm{Cu}$ (II) complex displayed a broad band $\left({ }^{2} \mathrm{E}_{\mathrm{g}} \rightarrow{ }^{2} \mathrm{~T}_{2 \mathrm{~g}}\right)$ with the absorption at $\sim 420 \mathrm{~nm}$, suggesting a distorted octahedral geometry due to the strong Jahn-Teller distortion of the $\mathrm{Cu}^{2+}$ ion. The elemental analysis confirmed the existence of $\mathrm{Cu}, \mathrm{C}, \mathrm{S}, \mathrm{N}$, and other elements in the synthesized mixed $\mathrm{Cu}$ (II) complex. The physicochemical studies of the organic ligand and $\mathrm{Cu}(\mathrm{II})$ complex were investigated by TG analysis, NMR, FTIR, SEM, EDX, electronic spectra and cyclic voltammetry measurements. The detection of chloride ions with the prepared mixed $\mathrm{Cu}$ (II) complex was studied by cyclic voltammetry measurements at different scan rates.
\end{abstract}

Keywords: bidentate ligand; oxindole; sodium diethyldithiocarbamate; spectroscopic studies; chloride ion detection

\section{Introduction}

Various symmetrical and unsymmetrical multidentate organic ligands have played a crucial part in designing metal complexes via coordination with different metal ions [1]. The versatile design of various metal complexes has been observed due to their diverse oxidation states and coordination properties [2,3]. The metal complexes have been widely used as drugs and diagnostic agents because they have shown easy interactions with different biomolecules and hence contributed to the development of new therapeutic or diagnostic agents [4,5]. In various biological systems, copper shows many spectral and chemical properties due to the presence of different organic ligands in the coordination sphere [6]. The novel oxindole derivatives have been extensively explored and investigated for various biological applications $[7,8]$. The cyclization reaction of various 
oxindole-derivatives is applied to the construction of C-C bonds [9-12]. The functionalization of various $\mathrm{C}-\mathrm{H}$ bonds of oxindole-derivatives has been reported as oxidative coupling of $\mathrm{C}-\mathrm{H}$ bonds, Heck reaction, etc. for economical and elegant applications [13-16]. Various transition metal complexes have been explored in several applications as optoelectronics [17,18], semiconductors [19], biochemistry [20] and sensors for polymer membranes [21-23]. However, the nitrogen-containing macrocycles exhibit high affinity towards metal ions for coordination [24].

In this study, the synthesis and various spectroscopic studies were performed for a novel mixed $\mathrm{Cu}$ (II) complex: the as-synthesized organic ligand named $1 H, 1^{\prime} H, 1^{\prime \prime} H-\left[2,3^{\prime}: 2^{\prime}, 3^{\prime \prime}\right.$-terbenzo[b]pyrrol]$2^{\prime \prime}\left(3^{\prime \prime} H\right)$-one (L1) and the well-known diethyldithiocarbamate (DTC) ligand (L2) mixed with copper (II) chloride dihydrate (2:1:1 ratio) in methanol solvent to produce the target $\mathrm{Cu}$ (II) complex. The electrochemical investigation of the novel $\mathrm{Cu}$ (II) complex was studied by cyclic voltammetry $(\mathrm{CV})$ in a three-electrode system by using tetrabutylammonium hexafluorophosphate $\left(\mathrm{TBAPF}_{6}\right)$ as a supporting electrolyte. The prepared $\mathrm{Cu}$ (II) complex was utilized as electrode materials for the electrochemical detection of chloride ions $\left(\mathrm{Cl}^{-}\right)$using $\mathrm{NaCl}(10 \mu \mathrm{L}, 0.1 \mathrm{M})$ in a standard buffer solution $(\mathrm{pH}=7)$ with different scan rates.

\section{Materials and Methods}

\subsection{Materials and Methods}

All reagents and chemicals were of analytical grade and used as received unless otherwise noted. The obtained metal complex was purified by recrystallization in hexane. The sodium diethyldithiocarbamate (L2) and Cu (II) chloride dihydrate were obtained from Sigma-Aldrich, St. Louis, Missouri, United States.

\subsection{Characterizations}

The optical properties of the synthesized complex were studied by ultraviolet-visible (UV-Vis) spectroscopy (V-670, JASCO spectrophotometer, Japan) at room temperature. To identify the various phases of solid material, X-ray powder diffraction (XRD, Rigaku, $\mathrm{Cu} \mathrm{K} \alpha, \lambda=1.54178 \AA$, Tokyo, Japan) was applied in the Bragg angle range of $\sim 10^{\circ}$ and $\sim 80^{\circ}$. The nature of the various chemical bonds and functional groups were investigated by Fourier transform infrared (FTIR, Nicolet, IR300 Thermo Fisher Scientific, Waltham, MA, USA) spectra and elemental analysis (EA Thermal analyzer, Thermo Fisher Scientific, Waltham, MA, USA). Field emission scanning electron microscopy (FESEM, Hitachi 4800, Tokyo, Japan) was used for morphology, and energy-dispersive X-ray (EDX) spectroscopy coupled with FESEM was applied to determine the elemental analysis. Cyclic voltammetry (CV) was used to find out the oxidation states and redox behavior of the $\mathrm{Cu}$ (II) complex by using WPG 100 Potentiostat/Galvanostat (WonATech, Seoul, Korea). In the three-electrode system, the CV experiments were executed in $0.1 \mathrm{M}$ tetrabutyl ammonium hexafluorophosphate $\left(\mathrm{TBAPF}_{6}\right)$ as supporting electrolytes an acetonitrile solution with ferrocene as an internal reference. The metal complex deposited on glassy carbon (GCE) was used as a working electrode, and a saturated calomel reference electrode (SCE) and a platinum wire as a counter electrode at $\sim 100 \mathrm{mV} / \mathrm{s}$ scan rate during the experiment.

\subsection{Synthesis of Ligand}

The heterocyclic organic ligand (L1) was synthesized by a single-step cyclization condensation reaction from oxindole in the presence of $\mathrm{POCl}_{3}$ at reflux temperature [25]. The $\mathrm{Cu}$ (II) complex (Scheme 1) was synthesized using $\mathrm{CuCl}_{2} \cdot 2 \mathrm{H}_{2} \mathrm{O}$ as the precursor and sodium diethyldithiocarbamate as a secondary ligand (L2). The structures of both the ligands and their $\mathrm{Cu}$ (II) complex (Figure 1) were characterized by the various spectroscopic studies. 

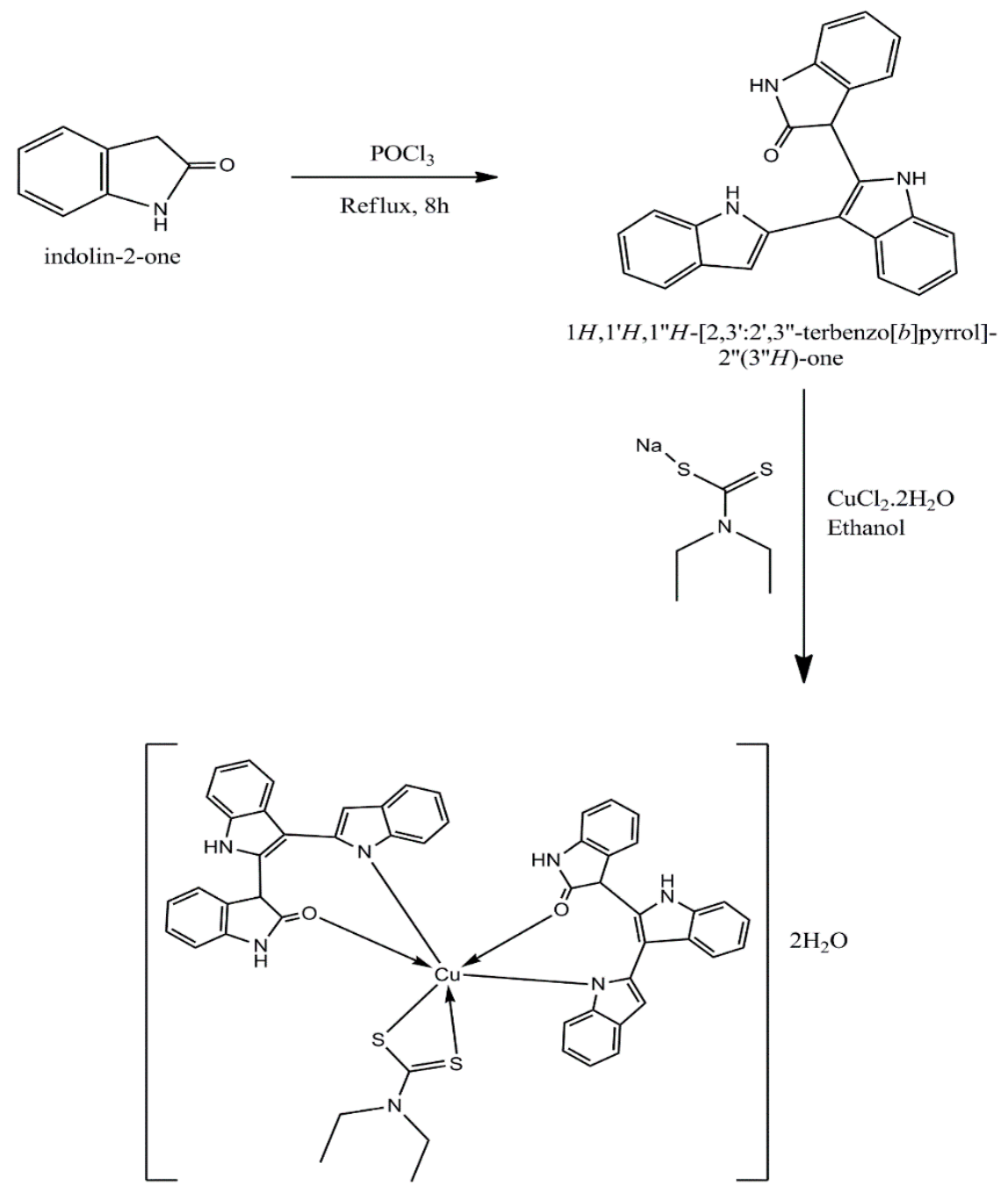

Scheme 1. Synthesis of mixed-ligand $\mathrm{Cu}$ (II) complex of oxindole-based organic ligand (L1) and dithiocarbamate (L2).

\subsubsection{Synthesis of Organic Ligand $\left(1 H, 1^{\prime} H, 1^{\prime \prime} H-\left[2,3^{\prime}: 2^{\prime}, 3^{\prime \prime}\right.\right.$-terbenzo[b]pyrrol]-2"(3" $\left.H\right)$-one) (L1)}

The oxindole $(1.0 \mathrm{~g}, 7.5 \mathrm{mmol})$ and $\mathrm{POCl}_{3}(10 \mathrm{~mL})$ were added into a round bottom flask and then refluxed for $8 \mathrm{~h}$ under an inert atmosphere. After completion, the reaction was cooled to room temperature and poured into ice water followed by dropwise addition of $\mathrm{KOH}$ solution (aq.) to adjust the $\mathrm{pH}$ of the reaction mixture. The brown precipitate obtained was filtered, dried and purified by silica gel column (hexane:dichloromethane, 1:1) chromatography to get L1 (30\% yield). Scheme 2 shows the electron delocalization behavior via keto-enol equilibrium in the ligand (L1) ${ }^{1} \mathrm{H}$ NMR (400 MHz, DMSO, ppm): $\delta 8.75(\mathrm{~s}, 1 \mathrm{H}), 8.42(\mathrm{~s}, 1 \mathrm{H}), 8.22(\mathrm{~d}, 2 \mathrm{H}), 8.10(\mathrm{~d}, 2 \mathrm{H}), 8.00(\mathrm{~s}, 1 \mathrm{H}), 7.80(1 \mathrm{H}), 7.76$ $(\mathrm{dd}, 2 \mathrm{H}), 7.63(\mathrm{~m}, 2 \mathrm{H}), 7.44(\mathrm{~m}, 1 \mathrm{H}), 7.00(\mathrm{~m}, 1 \mathrm{H}), 6.85(\mathrm{~m}, 2 \mathrm{H}), 6.61(1 \mathrm{H})$; IR $\left(\mathrm{KBr}, \mathrm{cm}^{-1}\right)$ : 3421, 3244, 3057, 2920, 2853, 1629, 1469, 1422, 1373, 1328, 1275, 1248, 1078, 1011, 917, 837, 774, 748, 730. Elemental analysis for $\mathrm{C}_{24} \mathrm{H}_{17} \mathrm{~N}_{3} \mathrm{O}$ is calculated as: $79.31 \%$ (carbon), $4.72 \%$ (hydrogen), $11.56 \%$ (nitrogen), $4.40 \%$ (oxygen); Found: 79.68\% (carbon), 4.86\% (hydrogen), 11.23\% (nitrogen), 4.23\% (oxygen).

\subsubsection{Synthesis of Metal Complex}

To a stirred methanolic ( $50 \mathrm{~mL}$, Sigma-Aldrich chemical) solution of ligand, L1 (762 mg, $2.1 \mathrm{mmol})$, the $\mathrm{CuCl}_{2} \cdot 2 \mathrm{H}_{2} \mathrm{O}(170 \mathrm{mg}, 1.0 \mathrm{mmol})$ was added with continuous stirring for $30 \mathrm{~min}$. Then sodium diethyldithiocarbamate $(172 \mathrm{mg}, 1.0 \mathrm{mmol})$ was added and the reaction continued for $4 \mathrm{~h}$ under an inert atmosphere. The precipitation of the metal complex was obtained after an addition of hexane 
(55\% yield). The product was filtered, washed with hexane and dried in a vacuum. ${ }^{1} \mathrm{H}$ NMR $(400 \mathrm{MHz}$, DMSO, ppm): $\delta 11.81(\mathrm{~s}, 2 \mathrm{H}), 8.64(\mathrm{~d}, 2 \mathrm{H}), 8.20(\mathrm{~d}, 4 \mathrm{H}), 7.91(\mathrm{~d}, 4 \mathrm{H}), 7.82(4 \mathrm{H}), 7.64(2 \mathrm{H}), 7.35(4 \mathrm{H}), 7.30$ $(4 \mathrm{H}), 6.86(2 \mathrm{H}), 5.76(\mathrm{~s}, 2 \mathrm{H}), 3.85(\mathrm{~s}, 2 \mathrm{H}), 3.71(\mathrm{q}, 4 \mathrm{H}), 3.32\left(\mathrm{H}_{2} \mathrm{O}\right), 2.49$ (DMSO), $1.22(\mathrm{t}, 6 \mathrm{H}) ; \mathrm{IR}(\mathrm{KBr}$, $\left.\mathrm{cm}^{-1}\right): 3420,3259,3060,2977,1698,1636,1560,1458,1382,1346,1279,1190,1152,1118,1070,1011,850$, 886, 748; Elemental analysis calculated as: $65.38 \%$ (carbon), 4.87\% (hydrogen), $10.07 \%$ (nitrogen), $6.59 \%$ (Sulphur), 6.57\% (oxygen), 6.53\% (Cu); Found: 66.27\% (carbon), 4.18\% (hydrogen), $9.70 \%$ (nitrogen), $4.18 \%$ (Sulphur), $6.17 \%$ (oxygen), $3.6 \%(\mathrm{Cu})$.
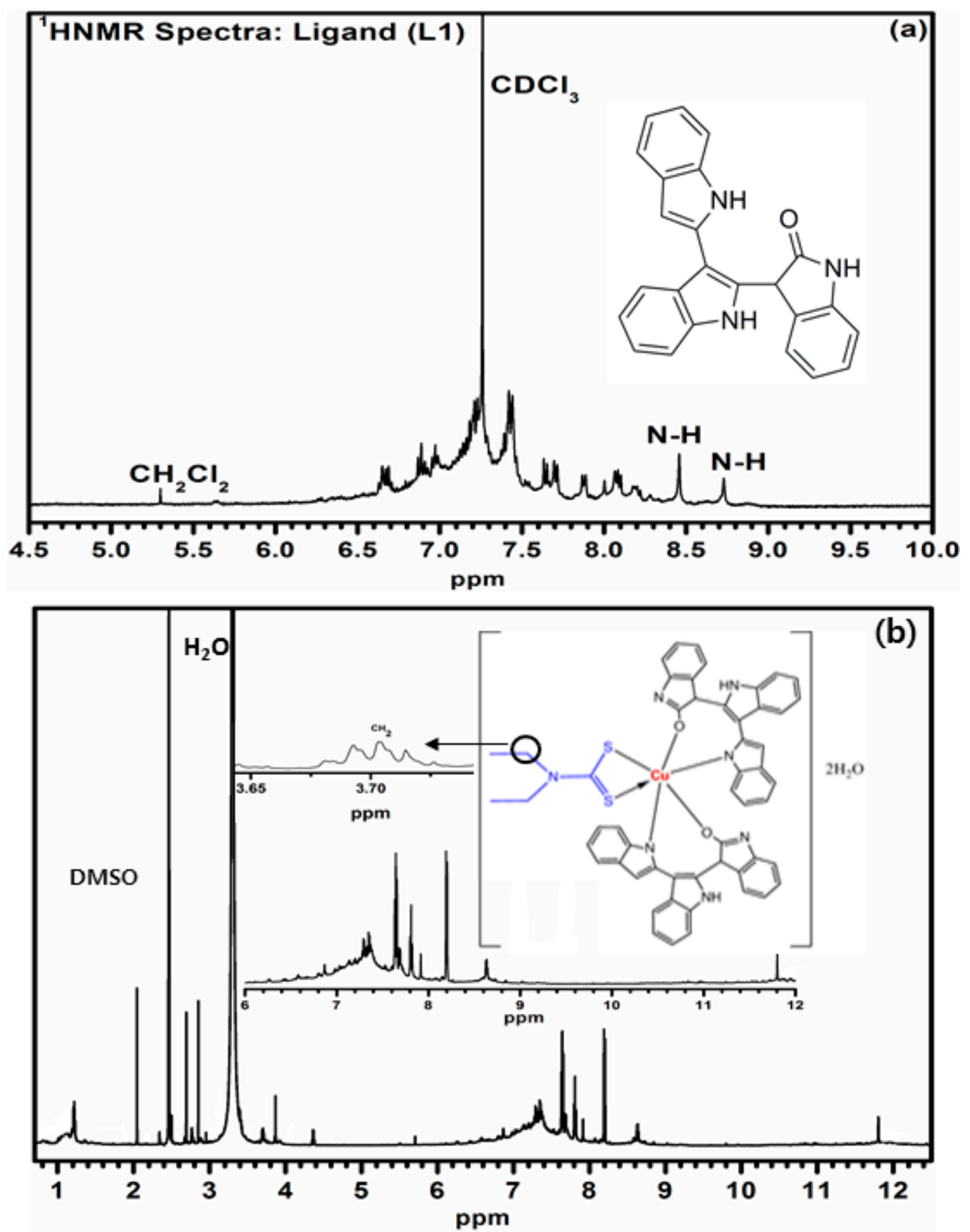

Figure 1. ${ }^{1} \mathrm{HNMR}$ spectra of the (a) ligand, L1 and (b) mixed ligand Cu (II) complex. 


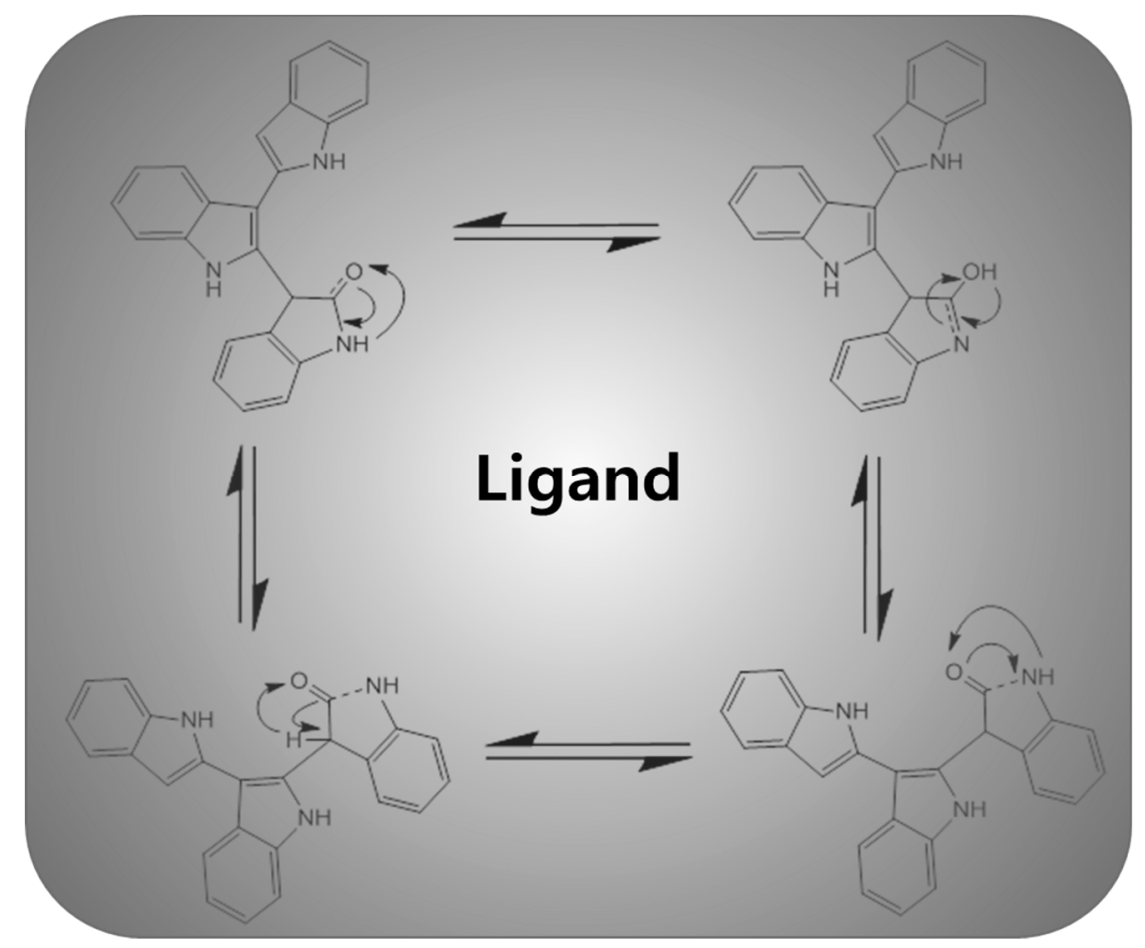

Scheme 2. Electron delocalization behavior via keto-enol equilibrium in the synthesized organic ligand (L1).

\subsection{Detection of Chloride Ions}

An indium tin oxide (ITO) substrate was cleaned and washed with acetone, ethanol and isopropanol followed by drying in an oven. The electrode surface was modified by spin-coating with $\mathrm{Cu}$ (II) solution $(0.1 \mathrm{M})$ at $1000 \mathrm{rpm}$ for $30 \mathrm{~s}$ and then dried in a vacuum. The as-prepared electrode was applied for electrochemical measurements (cyclic voltammetry) for chloride ion detection by using $\mathrm{NaCl}(0.1 \mathrm{M})$ solution in the standard buffer solution $(\mathrm{pH}=7)$ in a three-electrode system.

\section{Results and Discussion}

\subsection{Spectroscopic Studies of Ligand (L1) Cu (II) Complex}

\subsubsection{Nuclear Magnetic Resonance Spectroscopy}

${ }^{1} \mathrm{H}$ NMR spectrum (Figure 1a) of the synthesized organic ligand, L1, was observed in deuterated chloroform solvent and showed two singlet peaks at $8.4 \mathrm{ppm}$ and $8.6 \mathrm{ppm}$, assigned to $\mathrm{H}-\mathrm{N}-\mathrm{C}=\mathrm{O}$ cyclic ring. The singlet peak at $5.23 \mathrm{ppm}$ is assigned to the $\mathrm{C}-\mathrm{H}$ of dichloromethane which was used during the purification of L1. Additionally, the peaks of the aromatic protons of the ligand (L1) were observed in the range 6.67-8.42 ppm, while the doublet peaks appeared at 7.62-8.32 ppm corresponding to various benzene $\mathrm{C}-\mathrm{H}$ protons. Moreover, the origin of the chemical shift at $8.5 \mathrm{ppm}$ might be associated with the aromatic $\mathrm{C}-\mathrm{H}$ in position 3 of the indole nucleus. The synthesized organic ligand, L1, exhibits delocalization of electrons through $-\mathrm{NH}$ and $\mathrm{C}=\mathrm{O}$ groups to form tautomeric structures, as shown in Scheme 2. The signal in the range of 0.95-1.2 ppm has been observed for the methyl group of the coordinated diethyldithiocarbamate ligand (L2). The proton NMR spectra (Figure $1 \mathrm{~b}$ ) of mixed-ligand $\mathrm{Cu}$ (II) complex was observed in the deuterated dimethyl sulfoxide solvent with TMS as internal reference. The $-\mathrm{CH}_{2}$ protons of the diethyldithiocarbamate moiety is assigned at the $3.7 \mathrm{ppm}$ (quadruplet) of the $\mathrm{Cu}$ (II) complex [26]. The $\mathrm{O}=\mathrm{C}-\mathrm{NH}$ proton has been assigned the strong signal at $3.36 \mathrm{ppm}$ while attachment of third benzopyrrole moiety was observed due to the presence of a singlet peak at $4.34 \mathrm{ppm}$, hence a decrease in the chemical shift in the metal complex as compared to the organic ligand. The chemical shift values of other aromatic protons were observed in the region of 
7.32-8.23 ppm for the metal complex alongside the peak at 8.72 and $11.65 \mathrm{ppm}$ corresponding to the -NH proton of the cyclic benzopyrrole moiety [27].

\subsubsection{Fourier Transforms Infrared Spectroscopy}

The FTIR spectra in Figure 2a of the organic ligand (L1) showed a strong stretching band of the secondary amine $\mathrm{N}-\mathrm{H}$ group in the $3421-3249 \mathrm{~cm}^{-1}$ region for both the ligand and the metal complex. The disappearance of the $3495 \mathrm{~cm}^{-1}$ peak of the ligand confirms the attachment of the metal with the $\mathrm{N}-\mathrm{H}$ via coordination bond as the electron delocalization takes place in keto-enol forms of the synthesized organic ligand, L1. The neutral ligand indicates that the proton is bonded to the nitrogen atom instead of the oxygen and exhibits tautomeric structures (Scheme 2) which evidenced that the ketone form is more stable than the hydroxyl form. The peaks in the 3057-2905 $\mathrm{cm}^{-1}$ region were assigned to the $\mathrm{C}-\mathrm{H}$ stretching bands present in the synthesized oxindole-based ligand. The slightly lower shifting of the $\mathrm{C}=\mathrm{O}$ stretching band of the ligand from $1640 \mathrm{~cm}^{-1}$ to $1638 \mathrm{~cm}^{-1}$ in the metal complex might be due to the coordination bonding (ligand to metal bond) of the $\mathrm{O}$ atom to the $\mathrm{Cu}$ ion [28]. The characteristic $\mathrm{C}=\mathrm{S}$ peak of the dithiocarbamate ligand appeared in the region of $1328 \mathrm{~cm}^{-1}$, which shifted to the lower frequency of $1319 \mathrm{~cm}^{-1}$ on complexation with metal, indicating the $\mathrm{S}$ coordination attachment of the ligand. After complex formation with metal, the $\mathrm{C}=\mathrm{N}$ stretching peak (Table 1) also decreased to a low frequency from $1569 \mathrm{~cm}^{-1}$ to $1556 \mathrm{~cm}^{-1}$, suggesting $\mathrm{N}$ coordination towards the metal ion. The denticity of various ligands can ascertain the unsymmetrical monodentate or bidentate coordination via IR spectroscopy [29]. The single peak in the frequency region of $1020-950 \mathrm{~cm}^{-1}$ implies the bidentate attachment of the dithiocarbamate moiety with the metal ion. Additionally, the presence of a thioureide (N-CSS) peak around $1520 \mathrm{~cm}^{-1}$ in the metal complex indicates the presence of adjacent $\mathrm{C}-\mathrm{S}$ and $\mathrm{N}-\mathrm{C}$ bonds of the thiocarbamate ligand with a supporting C-S peak in the $1012 \mathrm{~cm}^{-1}$ region [30].
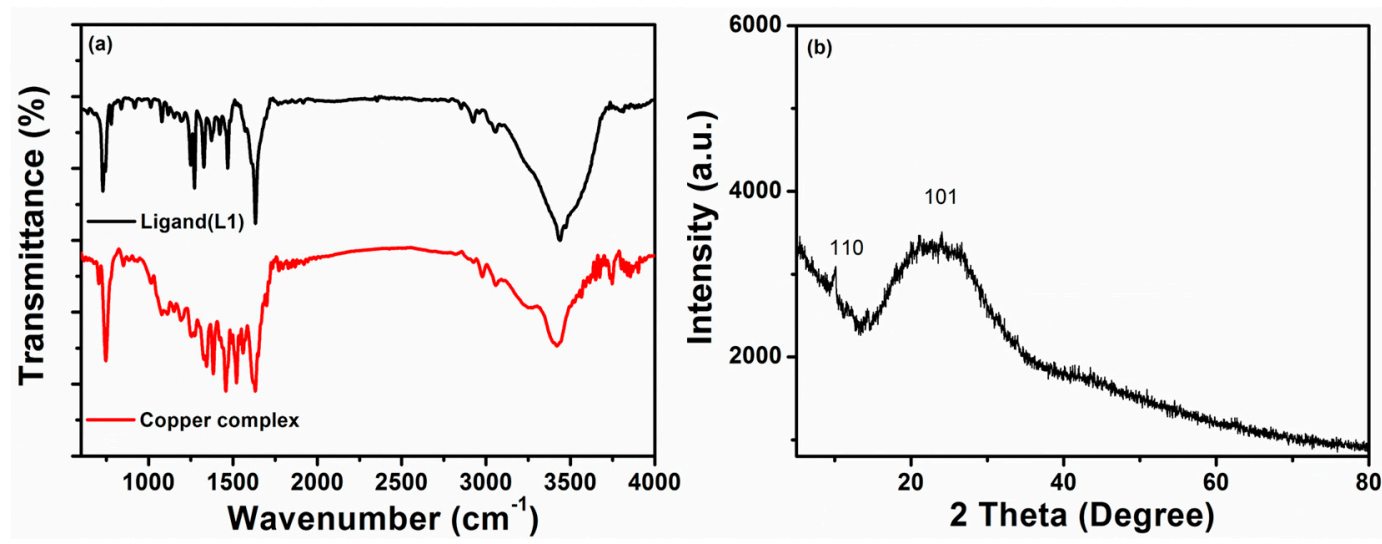

Figure 2. (a) FTIR spectra of organic ligand (L1) and Cu (II) complex and (b) powder XRD plot of mixed ligand $\mathrm{Cu}$ (II) complex.

Table 1. Characteristic IR bands $\left(\mathrm{cm}^{-1}\right)$ of the organic ligand (L1) and its $\mathrm{Cu}$ (II) complex with $\mathrm{KBr}$ pellets as reference.

\begin{tabular}{cccccccc}
\hline Compounds & $v(\mathrm{~N}-\mathrm{H})$ & $v(\mathrm{C}-\mathrm{H})$ & $v(\mathrm{C}=\mathrm{O})$ & $v(\mathrm{C}=\mathrm{N})$ & $v(\mathrm{C}=\mathrm{S})$ & $v(\mathrm{C}-\mathrm{O})$ & $v(\mathrm{C}=\mathrm{C})$ \\
\hline Ligand(L1) & 3459 & $2865-2964$ & 1640 & 1569 & 1328 & 1170 & 1275 \\
{$\left[\mathrm{Cu}(\mathrm{L} 1)_{2}(\mathrm{~L} 2)\right]$} & 3249 & $2850-2982$ & 1638 & 1556 & 1319 & 1172 & 1266 \\
\hline
\end{tabular}

\subsubsection{Powder X-Ray Diffraction Analysis}

XRD spectral study of the $\mathrm{Cu}$ (II) complex is shown in Figure 2b. The XRD pattern of the metal complex shows a small peak at $10.13^{\circ}$ and a broad peak at $24.02^{\circ}$, indicating that the metal complex has a low crystalline nature and is expected to have a solid amorphous state. 


\subsection{Electronic Properties of $\mathrm{Cu}$ (II) Complex}

Electronic spectra (Figure 3a) of the ligand (L1) showed two absorption peaks in chloroform. The broad peak around 220-246 might be assigned to the $\pi-\pi^{*}$ transition with a sharp peak at $302 \mathrm{~nm}$ to the $n-\pi^{*}$ electronic transitions. For the metal complex, three distinct absorption peaks were obtained in the chloroform solution. The high-intensity peak at $246 \mathrm{~nm}$ and a sharp peak at $300 \mathrm{~nm}$ corresponded to $\pi-\pi^{*}$ transitions and $n-\pi^{*}$ transition peaks of the organic ligand, which show a slight decrease in wavelength after metal complex formation. Additionally, the peak at $350 \mathrm{~nm}$ has been observed for the ligand to metal charge transfer (LMCT) transitions while the broad peak at $420 \mathrm{~nm}$ might be assigned to charge transfer transition $\left({ }^{2} \mathrm{E}_{\mathrm{g}} \rightarrow{ }^{2} \mathrm{~T}_{2 \mathrm{~g}}\right)$ due to the Jahn-Teller distortion of the geometry of the $\mathrm{Cu}$ (II) complex [31]. The obtained metal complex has shown strong solution stability in DMSO and DMF under the UV-Vis bands for a week. The electronic spectrum of the complex has shown a sharp peak at $217 \mathrm{~nm}$ and charge transfer (CT) peak at $293 \mathrm{~nm}$ in methanol. The intensity of the CT peak increased upon irradiation by UV light at $25^{\circ} \mathrm{C}$ without any other changes in the visible spectra of the $\mathrm{Cu}$ (II) complex [32]. The effects of various alcoholic solvents (Figure 3b) on the electronic spectra of the synthesized $\mathrm{Cu}$ (II) complex were also studied at the room temperature. Upon increasing the alkyl chain of the corresponding alcohols (ethanol to butanol), the slight blue shift in the peaks (211 and 207, respectively) and red shift in the peaks (295 and 298, respectively) were observed. However, the electronic spectra in isopropanol solution shows a peak at $209 \mathrm{~nm}$ and a distinct sharp peak at $297 \mathrm{~nm}$ [33].
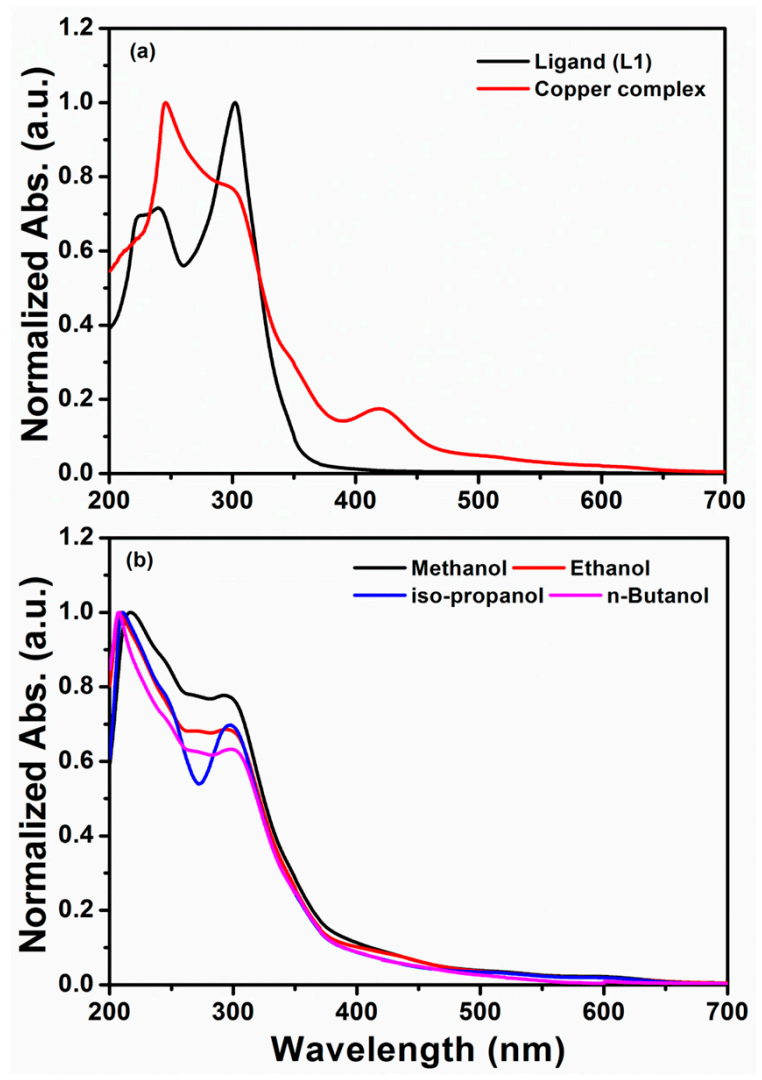

Figure 3. (a) Electronic spectra of the organic ligand, L1 and Cu (II) complex in chloroform solvent, (b) UV-visible spectra of $\mathrm{Cu}$ (II) complex in various alcoholic solvents.

\subsection{Thermal Properties of the Cu (II) Complex}

The thermogravimetric analysis (Figure 4a) of $\mathrm{Cu}$ (II) complex (empirical formula- $\mathrm{C}_{53} \mathrm{H}_{44} \mathrm{CuN}_{7} \mathrm{O}_{4} \mathrm{~S}_{2}$ ) reveals the decomposition of water molecules around $115^{\circ} \mathrm{C}$. The $\mathrm{Cu}$ (II) complex showed its first decomposition (Scheme 3) around the temperature range of $100-160{ }^{\circ} \mathrm{C}$ with $11.12 \%$ weight loss which 
might be due to the loss of water molecules with the diethyl amine fraction of diethyldithiocarbamate ligand, L2. But the second decomposition of $8.88 \%$ weight loss in the temperature range of $160-234{ }^{\circ} \mathrm{C}$ occurred owing to the loss of the carbon disulfide $\left(\mathrm{CS}_{2}\right)$ moiety of the remaining $\mathrm{L} 2$ ligand. The third decomposition of $14.61 \%$ weight loss was obtained in the temperature range of $240-392{ }^{\circ} \mathrm{C}$, which corresponds to the partial loss of the $\mathrm{C}_{8} \mathrm{H}_{5} \mathrm{~N}$ moiety of the organic ligand, L1. Finally, the fourth decomposition takes place around the temperature range of $395-465^{\circ} \mathrm{C}$ due to the loss of the remaining organic ligand and metal oxide formation with carbon as residue [34]. The observed decompositions conform with the calculated values of $\mathrm{Cu}$ (II) complex and its mass percentage-derivative (Figure $4 \mathrm{~b}$ ) during thermal analysis under an inert atmosphere.

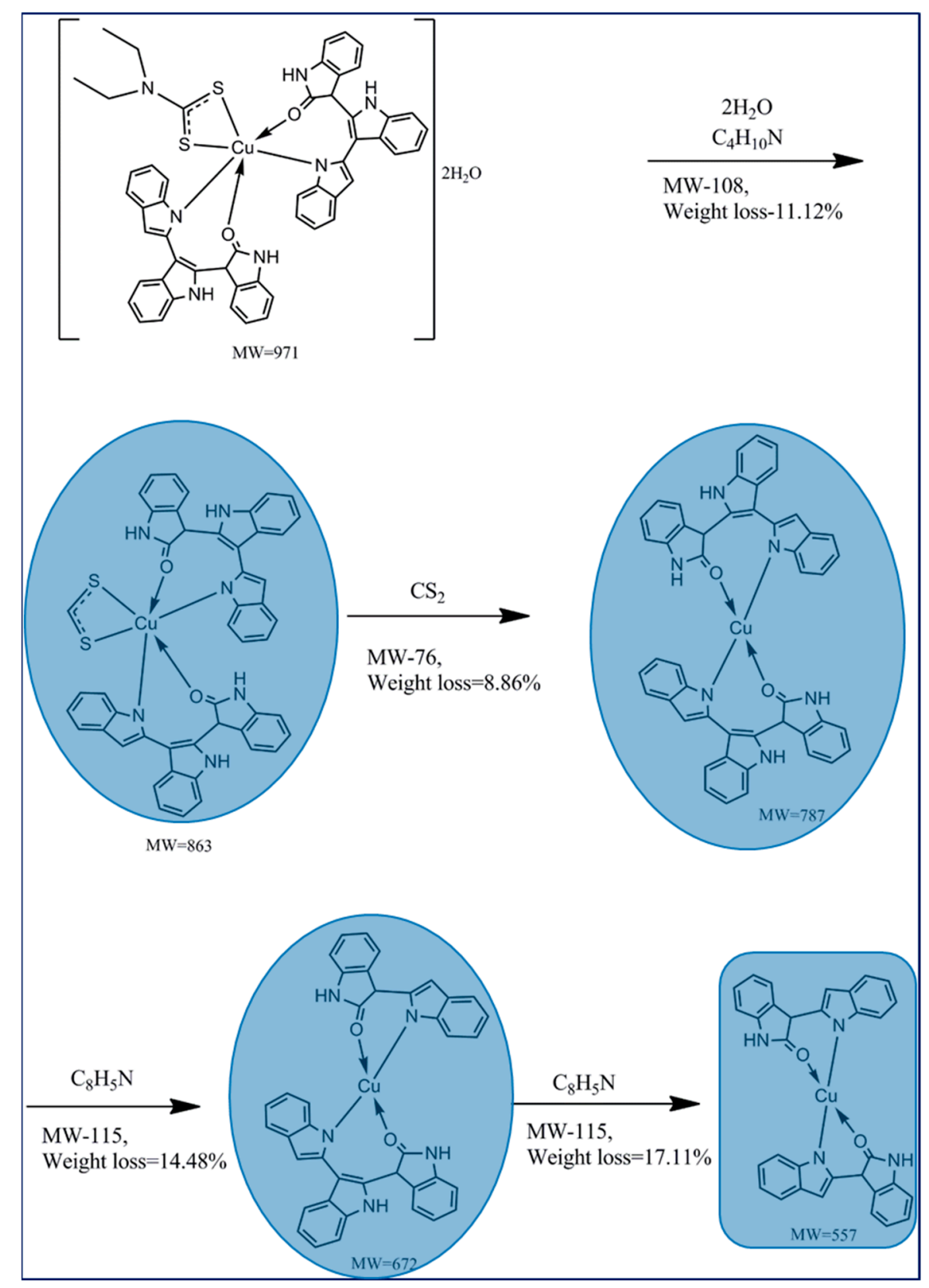

Scheme 3. Possible fragmentation pattern of the $\mathrm{Cu}$ (II) complex. 

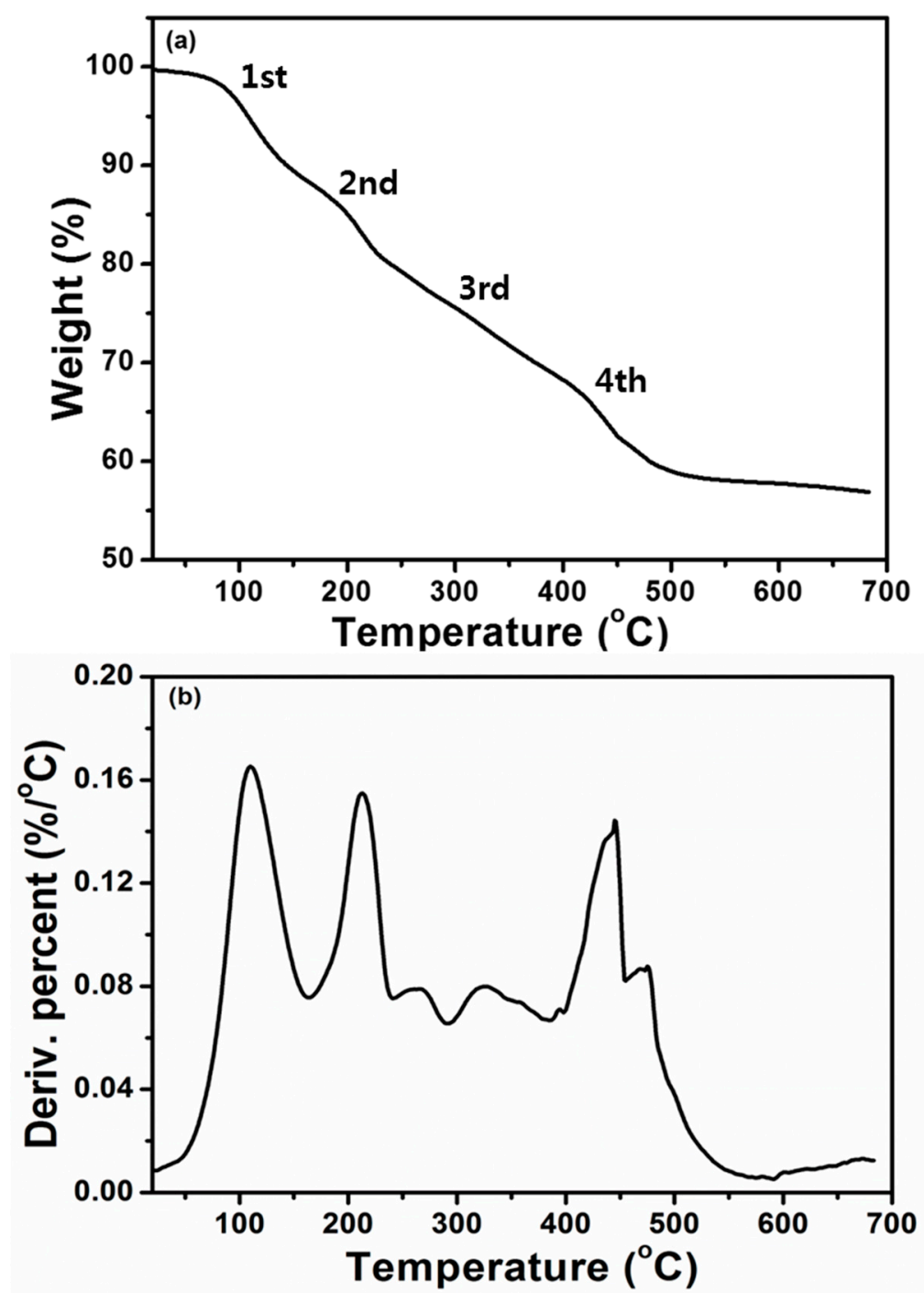

Figure 4. (a) Thermogravimetric analysis of $\mathrm{Cu}$ (II) complex with the scan rate of $10{ }^{\circ} \mathrm{C} / \mathrm{min}$ under nitrogen, (b) percent derivative curve of the $\mathrm{Cu}$ (II) complex.

\subsection{Scanning Electron Microscopic Analysis}

The SEM analysis was used to get the powder images of the $\mathrm{Cu}$ (II) complex as shown in Figure 5. The synthesized $\mathrm{Cu}$ (II) complex exhibits flower-like structures as observed in the SEM image of Figure $5 a$. The high-resolution image (Figure $5 b$ ) evidenced that the metal complex contains various types of nanoparticles with a micron diameter size. However, small-size nanoparticles are grouped to agglomerates and form large particles as shown in the high-resolution SEM image.

\subsection{Electrochemical Analysis of $\mathrm{Cu}$ (II) Complex}

To explore the electrochemical properties (Figure 6) of the $\mathrm{Cu}$ (II) complex, cyclic voltammetry was employed in a three-electrode system. The cyclic voltammograms of $\mathrm{Cu}$ (II) complex were recorded at a glassy carbon electrode in $\mathrm{CH}_{3} \mathrm{CN}$ containing $0.1 \mathrm{M} \mathrm{TBAPF}_{6}$ as a supporting electrolyte in the potential range from $-1.6 \mathrm{~V}$ to $+1.6 \mathrm{~V}$ with a scan rate of $100 \mathrm{mV} \mathrm{s}^{-1}$. The $\mathrm{Cu}$ (II) complex shows three reduction peaks with Epa values of $+0.412,-0.96$, and $-1.36 \mathrm{~V}$ vs. SCE. Hence, the irreversible reduction process of the $\mathrm{Cu}$ (II) complex leads to the deposition of $\mathrm{Cu}(0)$ on the electrode surface [35]. The peak potential $(+0.412 \mathrm{~V})$ might be attributed to the reduction of $\mathrm{Fc}^{+} / \mathrm{Fc}$, whereas the peak potential $(-1.00 \mathrm{~V})$ can be assigned to the reduction of $\mathrm{Cu}^{+} / \mathrm{Cu}$. Additionally, the third reduction potential $(-1.36 \mathrm{~V})$ might be ascribed to the $\mathrm{Cu}(\mathrm{II}) / \mathrm{Cu}(\mathrm{I})$ reduction process. During the reverse scan, three oxidation peaks of 
$-0.64,+0.38,+0.47 \mathrm{~V}$ vs. $\mathrm{Ag} / \mathrm{AgCl}$ were observed. The first peak $(\mathrm{Epc}-0.64 \mathrm{~V})$ is associated with the oxidation peak of $\mathrm{Cu}(\mathrm{I}) / \mathrm{Cu}$ (II) while the second peak $(+0.38 \mathrm{~V})$ is associated with the ligand $\mathrm{L}$. In addition, the third peak is assigned to the reference redox couple of $\mathrm{Fc} / \mathrm{Fc}^{+}$[36].

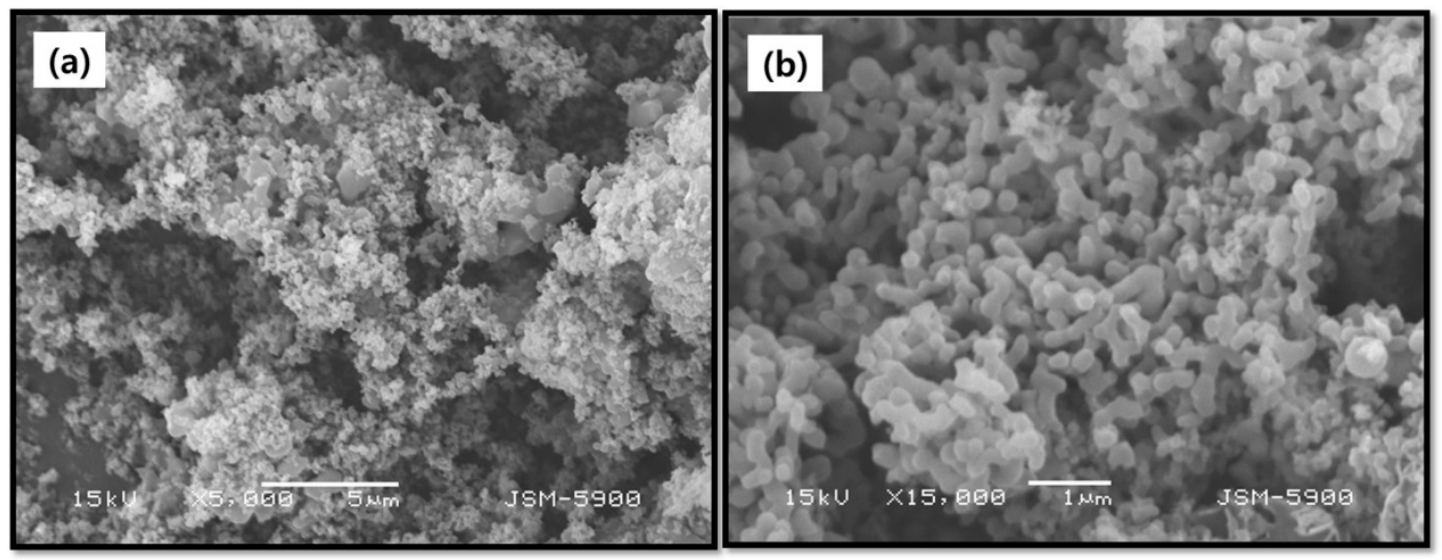

Figure 5. SEM images: (a) low resolution, and (b) high resolution of the mixed ligand Cu (II) complex.

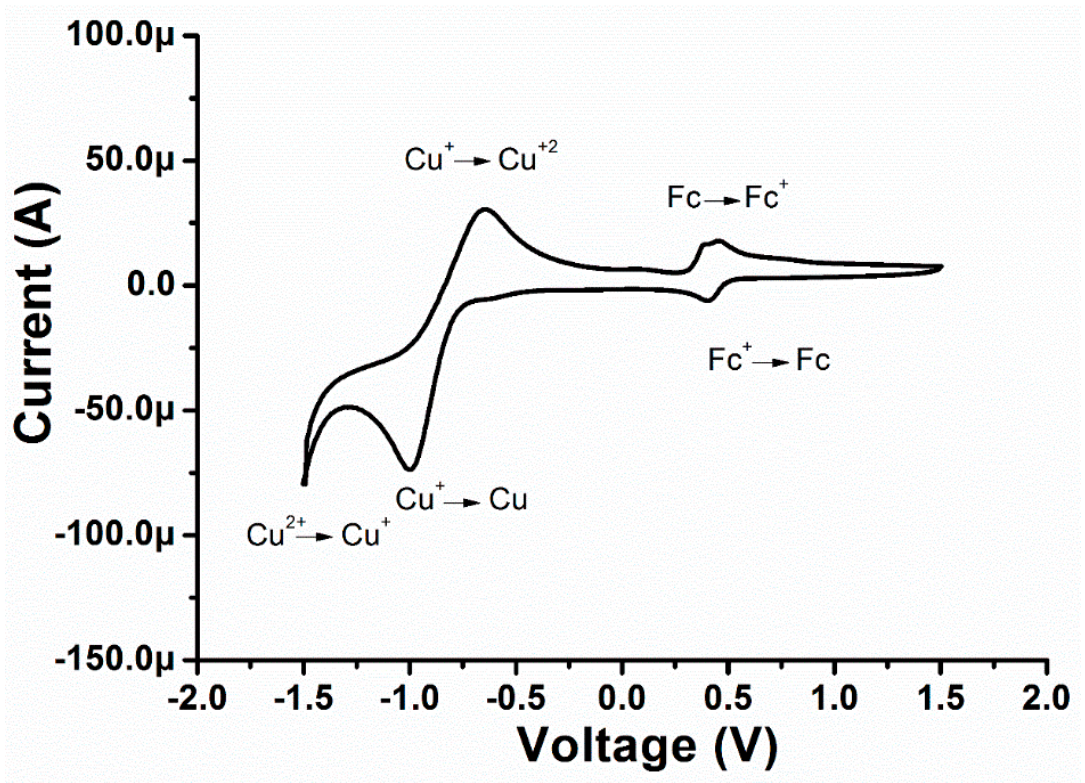

Figure 6. Cyclic voltammograms of the $\mathrm{Cu}$ (II) complex in $\mathrm{CH}_{3} \mathrm{CN}\left(0.1 \mathrm{~mol} \mathrm{~L}^{-1} \mathrm{TBAPF}_{6}\right)$, glassy carbon working electrode, $\mathrm{Ag} / \mathrm{AgCl}$ reference electrode and platinum wire electrode with scan rate $100 \mathrm{mV} \mathrm{s}^{-1}$.

\subsection{Electrochemical Chloride Ion Detection by the Cu (II) Complex}

For extensive electrochemical application, the prepared mixed $\mathrm{Cu}$ (II) complex was used for the detection of chloride ions by adding a fixed amount of $\mathrm{NaCl}$ in a standard buffer solution $(\mathrm{pH}=7)$ via cyclic voltammetry (CV). The electrochemical properties of $\mathrm{Cu}$ (II) complex were investigated by using the three-electrode system in the potential range from $+0.80 \mathrm{~V}$ to $-0.80 \mathrm{~V}$ in a standard buffer $(\mathrm{pH}=7)$ at various scan rates. The $\mathrm{CV}$ plots (Figure 7) of $\mathrm{Cu}$ (II) complex have shown two peaks in the standard buffer $(\mathrm{pH}=7)$ electrolyte. The cathodic peak was obtained in the forward scan and anodic peak during the reverse scan of $\mathrm{CV}$ measurements. 

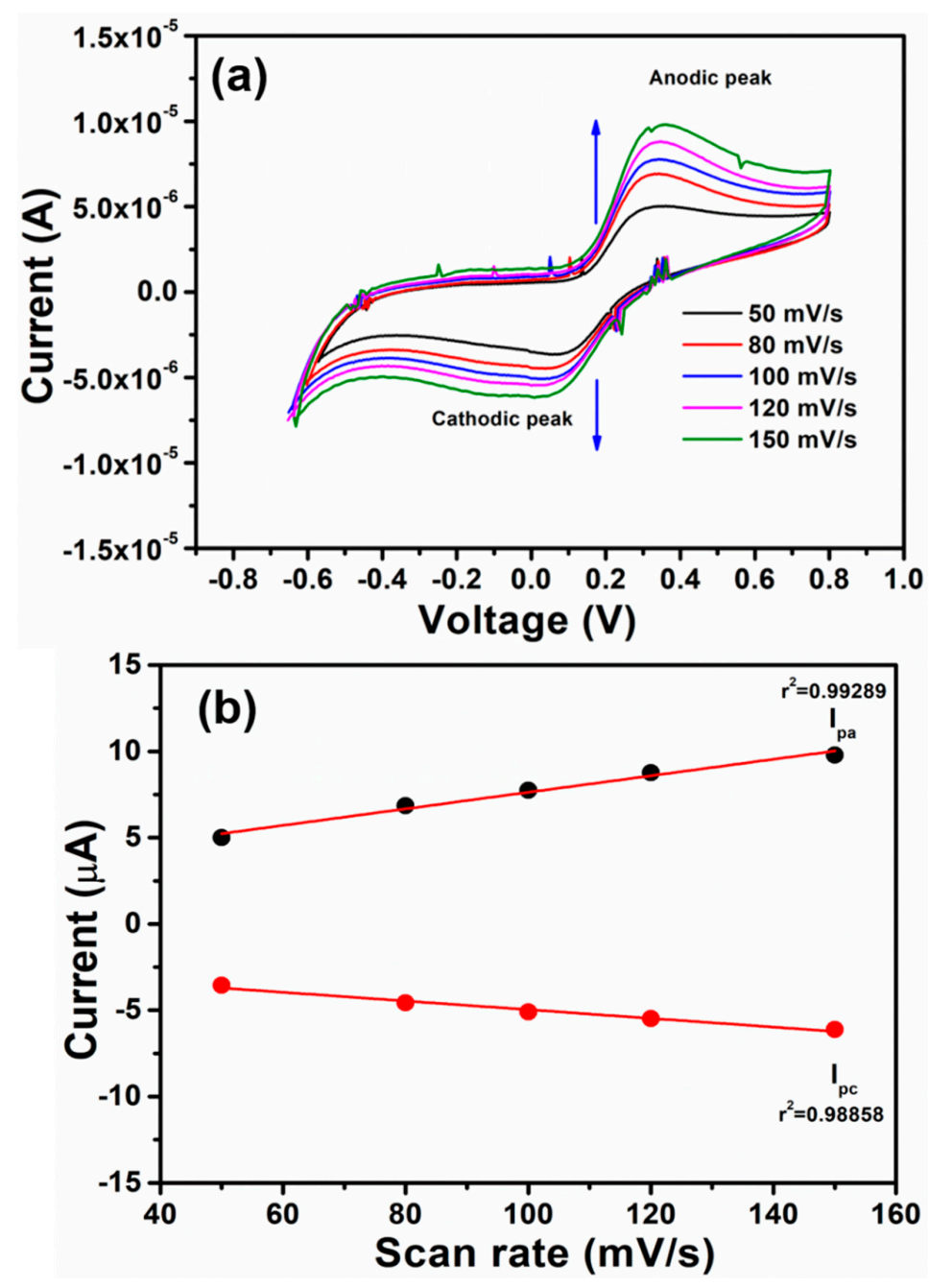

Figure 7. (a) Cyclic voltammograms of $\mathrm{Cu}$ (II) complex in $\mathrm{NaCl}(0.1 \mathrm{M})$ and phosphate buffer $(\mathrm{pH}=7)$ solution at different scan rate and $(\mathbf{b})$ variation of cathodic and anodic current with respect to scan rate.

The cathodic and anodic currents increased with the increase in scan rate from $50 \mathrm{mVs}^{-1}$ to $150 \mathrm{mV} / \mathrm{s}$. Furthermore, the cathodic potential $\left(\mathrm{E}_{\mathrm{pc}}\right)$ is shifted towards more negative potentials, and the anodic potential $\left(\mathrm{E}_{\mathrm{pa}}\right)$ moved to more positive potentials with increasing scan rates towards the detection of chloride ions [37]. The plot of anodic and cathodic peaks versus scan rates (Figure $7 \mathrm{~b}$ ) has shown a linear dependence relation and hence suggests a quasi-reversible nature and diffusion-controlled transfer of electrons during the electrochemical reaction. The electrochemical system shows excellent retention coefficients $\left(\mathrm{r}^{2}\right)$ of 0.99246 and 098866, respectively, which again deduces the good detection of chloride ions in neutral buffer electrolytes $[38,39]$.

\section{Conclusions}

The present work reports the synthesis of a novel $\mathrm{Cu}$ (II) complex by the reaction of bidentate ligands newly-synthesized oxindole-derivative and dithiocarbamate with hydrated transition metal chloride, $\mathrm{CuCl}_{2} \cdot 2 \mathrm{H}_{2} \mathrm{O}$ salts. The $\mathrm{Cu}$ (II) complex has shown a distorted octahedral geometry due to the presence of strong Jahn-Teller Distortion resulting in the three electronic transitions. The powder morphology of the $\mathrm{Cu}$ (II) complex using SEM analysis showed that the particles were agglomerated and matched elemental compositions. The obtained $\mathrm{Cu}$ (II) complex has shown irreversible redox properties with two reduction peaks and good stability in DMSO and DMF solution phases. The mixed $\mathrm{Cu}$ (II) complex exhibits the high cathodic and anodic current in chloride containing a neutral buffer, indicating the excellent ability of the complex for the detection of chloride ions. 
Author Contributions: M.N., A., S.A., M.S.A. and H.-S.S. conceived and designed the experiments; M.N., A. and S.A., performed the experiments, and analyzed the data contributed reagents/materials/analysis tools, wrote and revise the paper.

Acknowledgments: Sadia Ameen acknowledges NRF Project\#2016R1D1A1B03934446. This work is also supported by NRF Project\#2017R1A2B2003381. This paper was supported by research funds for newly appointed professors of Chonbuk National University in 2018.

Conflicts of Interest: The authors declare no conflict of interest.

\section{References}

1. Wei, H.L.; Piou, T.; Dufour, J.; Neuville, L.; Zhu, J. Iodo-Carbocyclization of Electron-Deficient Alkenes: Synthesis of Oxindoles and Spirooxindoles. J. Org. Lett. 2011, 13, 2244-2247. [CrossRef]

2. Wu, T.; Mu, X.; Liu, G. Palladium Catalyzed Oxidative Arylalkylation of Activated Alkenes: Dual C-H Bond Cleavage of an Arene and Acetonitrile. Angew. Chem. Int. Ed. 2011, 50, 12578-12581. [CrossRef]

3. Qiu, K.; Chen, Y.; Rees, T.W.; Ji, L.; Chao, H. Organelle-targeting metal complexes: From molecular design to bio-applications. Coord. Chem. Rev. 2019, 378, 66-86. [CrossRef]

4. Borge, V.V.; Patil, R.M. Syntheses and characterization of copper metal complexes prepared from chalcone derivatives. Microchem. J. 2019, 145, 456-459. [CrossRef]

5. Zhou, F.; Liu, Y.L.; Zhou, J. Catalytic Asymmetric Synthesis of Oxindoles Bearing a Tetrasubstituted Stereocenter at the C-3 Position. J. Adv. Synth. Catal. 2010, 352, 1381-1407. [CrossRef]

6. Huters, A.D.; Styduhar, E.D.; Garg, N.K. Total syntheses of the elusive welwitindolinones with bicyclo[4.3.1] cores. Angew. Chem. Int. Ed. 2012, 51, 3758-3765. [CrossRef]

7. Ball-Jones, N.R.; Badillo, J.J.; Franz, A.K. Strategies for the enantioselective synthesis of spirooxindoles. Org. Biomol. Chem. 2012, 10, 5165-5181. [CrossRef]

8. Dalpozzo, R.; Bartoli, G.; Bencivenni, G. Recent advances in organocatalytic methods for the synthesis of disubstituted 2- and 3-indolinones. Chem. Soc. Rev. 2012, 41, 7247-7290. [CrossRef]

9. Klein, J.E.; Taylor, M.N.; Eur, R.J.K. Transition Metal Mediated Routes to 3,3 Disubstituted Oxindoles through Anilide Cyclisation. J. Org. Chem. 2011, 2011, 6821-6841. [CrossRef]

10. Jia, Y.X.; Kundig, E.P. Oxindole synthesis by direct coupling of $\mathrm{C}\left(\mathrm{sp}^{2}\right)-\mathrm{H}$ and $\mathrm{C}\left(\mathrm{sp}^{3}\right)$-H centers. Angew. Chem. Int. Ed. 2009, 48, 1636-1639. [CrossRef]

11. Perry, A.; Taylor, R.J.K. Oxindole synthesis by direct C-H, Ar-H coupling. Chem. Commun. 2009, 45, 3249-3251. [CrossRef]

12. Pugh, D.S.; Klein, J.E.M.N.; Perry, A.; Taylor, R.J.K. Preparation of 3-Alkyl-Oxindoles by Copper(II)-Mediated C-H, Ar-H Coupling Followed by Decarboxyalkylation. Synlett 2010, 934-938. [CrossRef]

13. Klein, J.E.M.N.; Perry, A.; Pugh, D.S.; Taylor, R.J.K. First C-H Activation Route to Oxindoles using Copper Catalysis. Org. Lett. 2010, 12, 3446-3449. [CrossRef] [PubMed]

14. Ueda, S.; Okada, T.; Nagasawa, H. Oxindole synthesis by palladium-catalysed aromatic C-H alkenylation. Chem. Commun. 2010, 46, 2462-2464. [CrossRef]

15. Schiffner, J.A.; Oestreich, M. All-Carbon-Substituted Quaternary Carbon Atoms in Oxindoles by an Aerobic Palladium(II)-Catalyzed Ring Closure onto Tri- and Tetrasubstituted Double Bonds. Eur. J. Org. Chem. 2011, 2011, 1148. [CrossRef]

16. Jaegli, S.; Dufour, J.; Wei, H.I.; Piou, T.; Duan, X.H.; Vors, J.P.; Neuville, L. Palladium-Catalyzed Carbo-Heterofunctionalization of Alkenes for the Synthesis of Oxindoles and Spirooxindoles. J. Org. Lett. 2010, 12, 4498-4501. [CrossRef]

17. Chauke, V.P.; Antunes, E.; Nyokong, T. Comparative behavior of conjugates of tantalum phthalocyanines with gold nanoparticles or single walled carbon nanotubes towards bisphenol A electrocatalysis. J. Electroanal. Chem. 2011, 661, 1-7. [CrossRef]

18. Hazra, S.; Majumder, S.; Fleck, M.; Aliaga-Alcalde, N.; Mohanta, S. Synthesis, molecular and supramolecular structures, electrochemistry and magnetic properties of two macrocyclic dicopper(II) complexes: Microporous supramolecular assembly. Polyhedron 2009, 28, 3707-3714. [CrossRef]

19. Premkumar, J.; Ramaraj, R. Photocatalytic reduction of dioxygen by colloidal semiconductors and macrocyclic cobalt(III) complexes in Nafion and cellulose matrices. J. Mol. Catal. A Chem. 1998, 132, 21-32. [CrossRef] 
20. Anbu, S.; Kandaswamy, M.; Suthakaran, P.; Murugan, V.; Varghese, B. Structural, magnetic, electrochemical, catalytic, DNA binding and cleavage studies of new macrocyclic binuclear copper(II) complexes. J. Inorg. Biochem. 2009, 103, 401-410. [CrossRef]

21. Singh, A.K.; Saxena, P.; Panwar, A. Manganese(II)-selective PVC membrane electrode based on a pentaazamacrocyclic manganese complex. Sens. Actuators B Chem. 2005, 110, 377-381. [CrossRef]

22. Sil, A.; Ijeri, V.S.; Srivastava, A.K. Coated-Wire Silver Ion-Selective Electrode Based on Silver Complex of Cyclam. Anal. Sci. 2001, 17, 477-479. [CrossRef]

23. Kumar, P.; Shim, Y.B. A novel Mg(II)-selective sensor based on 5,10,15,20-tetrakis(2-furyl)-21,23dithiaporphyrin as an electroactive material. J. Electroanal. Chem. 2011, 661, 25-30. [CrossRef]

24. Elmosallamy, M.A.F.; Fathy, A.M.; Ghoneim, A.K. Lead(II) Potentiometric Sensor Based on 1,4,8,11Tetrathiacyclotetradecane Neutral Carrier and Lipophilic Additives. Electroanalysis 2008, 20, 1241-1245. [CrossRef]

25. Li, X.C.; Wang, C.Y.; Wan, Y.; Lai, W.Y.; Zhao, L.; Yin, M.F.; Huang, W. A T-shaped triazatruxene probe for the naked-eye detection of $\mathrm{HCl}$ gas with high sensitivity and selectivity. Chem. Commun. 2016, 52, 2748-2751. [CrossRef] [PubMed]

26. Ramadan, S.; Hambley, T.W.; Kennedy, B.J.; Lay, P.A. NMR Spectroscopic Characterization of Copper(II) and Zinc(II) Complexes of Indomethacin. Inorg. Chem. 2004, 43, 2943. [CrossRef]

27. Shahzadi, S.; Ali, S.; Fettouhi, M. Synthesis, Spectroscopy, In Vitro Biological Activity and X-ray Structure of (4-Methylpiperidine-dithiocarbamato-S,S')triphenyltin(IV). J. Chem. Crystallogr. 2008, 38, 273. [CrossRef]

28. Gudasi, K.B.; Patil, S.A.; Kulkarni, M.V.; Nethaji, M. Transition metal complexes of a potential anticancer quinazoline ligand. Trans. Met. Chem. 2009, 34, 325. [CrossRef]

29. Fuentes-Martinez, J.P.; Toledo-Martinez, I.; Roman-Bravo, P.; Garcia, P.G.; Godoy-Alcantar, C.; Lopez-Cardoso, M.; Morales-Rojas, H. Diorganotin(IV) dithiocarbamate complexes as chromogenic sensors of anion binding. Polyhedron 2009, 28, 3953-3966. [CrossRef]

30. Tiekink, E.R.T. Tin dithiocarbamates: Applications and structures. Appl. Organomet. Chem. 2008, 22, 533-550. [CrossRef]

31. Mohamed, G.G. Synthesis, characterization and biological activity of bis(phenylimine) Schiff base ligands and their metal complexes. Spectrochim. Acta A 2006, 64, 188-195. [CrossRef]

32. Gup, R.; Giziroglu, E. Metal complexes and solvent extraction properties of isonitrosoacetophenone 2-aminobenzoylhydrazone. Spectrochim. Acta A 2006, 65, 719-726. [CrossRef]

33. Gatto, C.C.; Lang, E.S.; Burrow, R.A.; Abram, U. Syntheses and Structures of 2-Acetylpyridine-(2-aminobenzoylhydrazone) and its Dioxouranium(VI) Complex. J. Braz. Chem. Soc. 2006, 17, 1612-1616. [CrossRef]

34. Wong, W.W.H.; Curiel, D.; Lai, S.W.; Drew, M.G.B.; Beer, P.D. Ditopic redox-active polyferrocenyl zinc(II) dithiocarbamate macrocyclic receptors: Synthesis, coordination and electrochemical recognition properties. Dalton Trans. 2005, 774-781. [CrossRef] [PubMed]

35. Golcu, A.; Tumer, M.; Demirelli, H.; Wheatley, R.A. Cd(II) and Cu(II) complexes of polydentate Schiff base ligands: Synthesis, characterization, properties and biological activity. Inorg. Chim. Acta 2005, 358, 1785-1797. [CrossRef]

36. John, R.P.; Sreekanth, A.; Rajakannan, V.; Ajith, T.A.; Kurup, M.R.P. New copper(II) complexes of 2-hydroxyacetophenone N(4)-substituted thiosemicarbazones and polypyridyl co-ligands: Structural, electrochemical and antimicrobial studies. Polyhedron 2004, 23, 2549-2559. [CrossRef]

37. Shamsipur, M.; Roushani, M.; Pourmortazavi, S.M.; Shahabadi, N. Amperometric determination of sulfide ion by glassy carbon electrode modified with multiwall carbon nanotubes and copper (II) phenanthroline complex. Cent. Eur. J. Chem. 2014, 12, 1091-1099. [CrossRef]

38. Ramar, V.; Balaya, P. Enhancing the electrochemical kinetics of high voltage olivine LiMnPO4 by isovalent co-doping. Phys. Chem. Chem. Phys. 2013, 15, 17240-17249. [CrossRef] [PubMed]

39. Li, L.; Tang, X.; Liu, H.; Qu, Y.; Lu, Z. Morphological solution for enhancement of electrochemical kinetic performance of $\mathrm{LiFePO}_{4}$. Electrochim. Acta 2010, 56, 995-999. [CrossRef]

(C) 2019 by the authors. Licensee MDPI, Basel, Switzerland. This article is an open access article distributed under the terms and conditions of the Creative Commons Attribution (CC BY) license (http:// creativecommons.org/licenses/by/4.0/). 